\title{
BENTUK TUTURAN DIREKTIF DALAM AKUN TWITTER @FiersaBesari
}

\author{
Niken Thalia Ayupradani*1, Dini Restiyanti Pratiwi \\ 1,2Pendidikan Bahasa dan Sastra Indonesia, Fakultas Keguruan dan Ilmu Pendidikan, \\ Surakarta \\ ${ }^{1,2}$ Universitas Muhammadiyah Surakarta; Jl. A. Yani, Mendungan, Pabelan, Kartasura, \\ Sukoharjo, Jawa Tengah
}

Surel: ${ }^{1}$ a310170144@ student.ums.ac.id, ${ }^{2}$ drp122@ums.ac.id

\begin{abstract}
Abstrak
Tujuan dari penelitian ini yakni menemukan bentuk tuturan direktif serta jenisnya. Penelitian ini merupakan penelitian deskriptif kualitatif. Menggunakan sumber data dari kalimat dalam cuitan dalam akun twitter @ FiersaBesari selama bulan Januari 2021. Cuitan yang digunakan sebagai data adalah cuitan yang mengandung tururan direktif. Teknik pengumpulan data menggunakan cara dokumentasi, simak, dan catat. Tuturan direktif yang ditemukan dalam akun twitter @ FiersaBesari sebanyak 35 cuitan sekaligus digunakan sebagai data. Selanjutnya, hasil dalam penelitian ini dari 35 data, bentuk tuturan direktif dapat dikelompokkan dalam 4 jenis tutuan direktif yakni; 15 tindak tutur jenis mengingatkan, 10 jenis tuturan direktif menasehati, 6 jenis tuturan direktif mengajak, dan terakhir 4 jenis tuturan direktif menegur. Jenis tuturan yang paling banyak ditemukan yakni, tuturan direktif mengingatkan, selanjutnya baru diikuti menasehati, mengajak, dan menegur. Hal ini menandakan bahwa cuitan @FiersaBesariditujukan untuk memberikan efek berupa tindakan oleh mitra tutur.
\end{abstract}

Kata kunci: Media sosial, Tindak tutur direktif, Twitter

\begin{abstract}
The purpose of this study is to find the form of directive speech and its types. This research is a qualitative descriptive study. Using the data source from the sentences in the tweets in the @ FiersaBesari twitter account during January 2021. The tweets used as data are tweets containing directives. Data collection techniques use documentation, listen, and take notes. The directives found in the @ FiersaBesari twitter account as many as 35 tweets were also used as data. Furthermore, the results in this study from 35 data, the form of directive speech can be grouped into 4 types of directive speech, namely; 15 types of speech acts remind, 10 types of speech directive advising, 6 types of speech directive inviting, and finally 4 types of speech directive admonishing. The most common types of utterances are directive utterances to remind, then followed by advising, inviting, and reprimanding. This indicates that @ FiersaBesari's tweet is intended to have an effect in the form of actions by the speech partner.
\end{abstract}

Keywords: Social media, Directive speech acts, Twitter

\section{A. PENDAhuluan}

Interaksi yang terjadi antara penutur dan mitra tutur menghasilkan peristiwa tutur. Dalam kajian pragmatik, proses tersebut dikenal dengan istilah tindak tutur. Menurun Wengrum tindak tutur addalah sebuah kemampuan seseorang dalam menggunakan 
bahasa dalam sebuah proses komunikasi (Islamiati, Rita Arianti, 2020:261). Gunanya untuk menyampaikan pesan, tujuan, dan maksud tertentu dari penutur kepada mitra tutur. (Waljinah et al., 2019:119) tujuan daripada tindak tutur yakni keinginan dari penutur untuk menyampaikan sesuatu kepada mitra tutur menjadi beragam jenis tuturan sesuai dengan tujuan dari penutur. Pendapat lain pun mengemukakan bahwa tindak tutur berupa ujaran dari penutur yang ingin diterima oleh mitra tuturnya. Serta, implikator dijadikan sebuah tujuan dari ujaran yang dituturan oleh penutur (Qomariyah, 2017:2).

Tuturan yang memiliki pesan, tujuan, dan maksud tertentu tersebut tuturan yang bersifat pragmatik. Disebut bersifat pragmatik karena dalam berkomunikasi atau berinteraksi, selain memahami unsur bahasa pun dituntut untuk memahami unsur-unsur diluar bahasa. Unsur diluar bahasa yakni seperti yang disebutkan di atas seperti pesan, tujuan, dan maksud tuturan penutur kepada mitra tutur.

Adanya unsur diluar bahasa seperti pesan, tujuan, dan maksud, pragmatik membagi tindak tutur menjadi berbagai jenis. Searle (Prayitno, 2017:51) membagi menjadi lima jenis tindak tutur. Kelima jenis tindak tutur tersebut yakni tindak tutur representatif, direktif, komisif, ekspresif, dan deklaratif. Tindak tutur representatif adalah tindak tutur dalam suatu tingkatan tertentu mengikat penutur dalam proposisi yang diungkapkan.

Tindak tutur direktif, tuturan yang berupa usaha penutur agar mitra tuturnya melakukan suatu tindakan. Tindak tutur komisif merupakan tuturan yang menyatakan janji bahwa penutur akan melakukan tindakannya di masa yang akan datang. Tuturan ekspresif merupakan tuturan yang menggambarkan psikologis dalam keadaan tertentu. Tuturan deklaratif merupakan tuturan yang mengaitkan isi tuturan dengan kenyataan. Tindak tutur direktif merupakan suatu keinginan penutur untuk mitra tutur (K. E. Saputri et al., 2018:32).

Dari lima jenis tindak tutur, penelitian ini lebih fokus dalam menganalisis jenis tindak tutur direktir. (Prayitno, 2017:51) menyatakan bahwa tindak tutur direktif merupakan bentuk usaha dari penutur agar mitra tuturnya melakukan suatu tindakan. Bentuk-bentuk tindakan dalam tindak tutur direktif seperi; memerintah, menyuruh, meminta, memohon, mengundang, dan menasehati. Tindak tutur direktif dapat ditermukan baik secara lisan maupun tulisan. Selagi tuturan tersebut menghasilkan efek atau dampak yang meminta 
mitra tutur untuk melakukan sesuatu disebut tindak tutur direktif. Tuturan direktif dapat disampaikan oleh penutur baik secara lisan ataupun tulisan.

Tuturan direktif secara lisan disampaikan melalui suara. Adapun tindak tutur direktif secara tulis disampaikan melalui sebuah tulisan. Tuturan direktif tidak hanya ditemukan dalam kehidupan sehari-hari. Akan tetapi, tuturan direktif pun dapat ditemukan dalam media sosial. Ragam jenis media sosial seperti Instagram, twitter, facebook, telegram, dll. dapat dimanfaatkan untuk mendapatkan bentuk-bentuk tuturan direktif. Tuturan tersebut pun beragam. Terdapat tuturan secara lisan yang di dapat dari unggahan video, atau dapat pula berupa tulisan yang ditemukan dalam caption Instagram, atau cuitan twitter.

Berbagai temuan tindak tutur yang terdapat di berbagai jenis media sosial, penelitian ini berfokus pada tuturan direktif yang ada di twitter. Twitter merupakan salah satu jenis media sosial yang digunakan sebagai media untuk menyampaikan informasi. Di dalamnya, terdapat tuturan baik lisan maupun tulis. (Ramadhani \& Santoso, 2019:45) menyatakan bahwa twitter merupakan suatu layanan sosial media yang berkategori microblogging. Microblogging ini adalah sebuah layanan blog yang singkat dalam sebuah paragraf. Maka dari itu, twitter disebut sebagai tempat layanan informasi yang dapat kita bagikan kepada banyak orang.

Selain itu, twitter memiliki ketentuan tertentu seperti, satu kali tweet atau cuitan hanya mampu memuat 140 karakter saja. Cuitan yang memuat tulisan tersebut disampaikan oleh penutur yang disampaikan kepada mitra tutur atau followers-nya. Dimana tuturan tersebut sangat bervariasi.

Pengguna twitter berasal dari berbagai kalangan. Mulai dari remaja, dewasa, artis/public figure, sampai dengan tokoh-tokoh pemerintahan. Akun twitter yang dimiliki oleh public figure dan tokoh pemerintahan tentu banyak menyita perhatian warganet. Tak jarang, mereka memiliki jumlah followers yang lumayan banyak. Salah satu pengguna aktif di twitter yang dimiliki oleh seorang public figure adalah akun dari @FiersaBesari dengan jumlah followers 7,7 Juta. Akun ini menarik untuk dikaji bentuk tuturannya karena sering mencuitkan mengenai kata-kata motivasi. Kata-kata motivasi tersebut mengandung tindak tutur direktif. Fiersa Besari adalah seorang penulis, musisi, dan traveler dengan hobi mendaki gunung. 
Salah satu cuitan Fiersa tersaji pada data berikut. Fiersa pada, Sabtu (21/11/2020) mencuitkan "Gagal mewujudkan rencana bukan berarti bikin kami jadi manusia gagal,". Cuitan tersebut mengandung tuturan direktif menasehati. Karena dalam tuturan tersebut, Fiersa sebagai penutur menyampaikan kepada warganet atau mitra tuturnya untuk tidak terlalu terpuruk dalam kegagalan.

Penelitian mengenai tindak tutur direktif sudah banyak dilakukan baik dalam wacana naratif maupun tulisan. Penelitian ini membahas mengenai tindak tutur direktif dalam akun twitter@FiersaBesari dengan tujuan penelitian menemukan jenis tuturan direktif yang terdapat dalam cuitan @ FiersaBesari.

Beberapa penelitian sebelumnya yang telah mengkaji tentang tindak tutur direktif seperti, (Wulansari \& Suhartini, 2015) melakukan penelitian dengan judul "Directive Speech Acts Realization of Indonesian ELF Teacher". Penelitian tersebut menemukan hasil berupa tiga jenis tuturan direktif dalam pembelajaran ELF. (Nurkamto et al., 2016) melakukan penelitian mengenai tindak tutur direktif dengan judul "Pragmatic Study of Directive Speech Acts in Stories in Al Quran". Hasil penelitian tersebut menemukan enam bentuk tindak tutur direktif dalam Al-Quran. Serta, dengan tuturan jenis perintah yang paling banyak yakni 60 jenis. Selain itu, (Wulansari \& Suhartini, 2015) melakukan penelitian dengan judul “Directive Speech Acts Realization of Indonesian ELF Teacher". Penelitian tersebut menemukan hasil berupa tiga jenis tuturan direktif dalam pembelajaran ELF.

(Achsani, 2019) Melakukan penelitian mengenai tindak tutur direktif dengan judul "Tindak Tutur Diretif dan Implikatur Konvensional dalam Wacana Meme Dilan" memnemukan jenis tindak tutur seperti memerintah, menyarankan, menuntut dan memberi nasihat. Achsani memanfaatkan wacana meme dari film dilan sebagai sumber data. (Fitri et al., 2019) melakukan penelitian serupa dengan judul "Tindak Tutur Direktif dalam Kumpulan Cerpen Lukisan Kaligrafi Karya A. Mustofa Bisri serta Implementasi Pembelajaran Teks Anekdot di SMA". Hasil penelitian tersebut ditemukan enam jenis tindak tutur direktif. Serta, menemukan tuturan direktif memberi nasihat dengan jumlah yang paling banyak. 


\section{B. KAJIAN TEORI}

Tindak tutur memiliki suatu tujuan (Waljinah et al., 2019:119) menyatakan bahwa keinginan dari penutur untuk menyampaikan sesuatu kepada mitra tutur menjadi beragam jenis tuturan sesuai dengan tujuan dari penutur. Selain itu, terdapat pendapat lain yang mengemukakan bahwasannya tindak tutur merupakan suatu ujaran dari penutur yang tujuannya tuturannya ingin diterima oleh mitra tuturnya (Qomariyah, 2017:2).

Selain itu, tindak tutur memiliki pembagian lain yakni tindak tutur direktif. Menurut (Larassaty et al., 2016:432) tindak tutur direktif merupakan jenis tuturan yang dimanfaatkan oleh penutur untuk menyuruh lawan atau mitra tutur agar melakukan sesuatu. Selain itu, pendapat dari (Prayitno, 2017:51) pun menyatakan bahwa tindak tutur direktif suatu bentuk usaha dari penutur agar mitra tuturnya melakukan suatu tindakan yang berasal dari tuturannya. (Islamiati, Rita Arianti, 2020) menuturkan bahwasannya tindak tutur direktif adalah suatu tuturan yang dapat memberikan sebuah efek berupa tindakan yag diinginkan oleh penutur. Tindak tutur direktif merupakan suatu respon yang muncul dari mitra tutur. Hal tersebut merupakan efek yang diterima mitra tutur setelah mendapat tuturan direktif dari penutur (Ilmiah \& Affandy, 2017:108).

Searle dalam (Sudarto, 2018:87) mengelompokkan menjadi enam tindak tutur direktif yakni pertanyaan seperti, permintaan; meminta, memohon, menekan, dan lain-lain. Kedua, pertanyaan; bertanya, berinkuiri, dan menginterogasi. Ketiga, pelarangan; melarang dan membatasi. Keempat, perintah; memerintah, menghendaki, mengkomandokan, dan lain-lain. Kelima, persetujuan; menyetujui, mengabulkan, mengizinkan, dan lain-lain. Sertan keenam, nasihat; menasehati, memperingatkan, mengusulkan, dan lain-lain.

Terdapat lima jenis tindak tutur direktif menurut (Larassaty et al., 2016:432) yakni memohon, menyuruh, menyarankan, menuntut, dan menantang. Selain itu (Prayitno, 2017:23) mengklasifikasikan tindak tutur direktif dalam sub-sub tindak tutur direktif menjadi 29 sub: menyuruh, menasihati, meminta izin, permisi, menguji, meminta restu, melamar, mengingatkan, melerai, memaksa, merayu, menantang, menyarankan, memohon, menyumpah, merekomendasi, memperingatkan, menganjurkan, mengharap, mengajak, mendesak, menginterupsi, menegur, memarahi, menagih janji, membujuk, mempersilahkan, mengusir, dan melarang. 


\section{METODE PENELITIAN}

Penelitian ini merupakan penelitian kualittatif deskriptif, yang mana penyajian datanya merupakan kumpulan kata dan kalimat. Objek penelitian penelitian ini merupakan bentuk cuitan aatau tweet dari akun @FiersaBesari yang mengandung tuturan direktif. Data dalam penelitian ini mengambil kalimat-kalimat cuitan dari akun @FiersaBesari yang mengacu pada tuturan direktif. Teknik untuk pengumpulan data menggunakan tiga cara yakni dokumentasi, simak, dan catat. Ketiganya diungsikan secara berkesinambungan mulai dari dokumentasi untuk merekam data berupa tangkapan layar dari cuitan, simak difungsikan untuk menyimak cuitan Fiersa yang mengandung tuturan direktif, sedangkan catat yakni untuk mencatat tuturan direktif yang ada dalam akun Fiersa. Analisis data menggunakan metode agih. (Sudaryanto, 2015) metode agih merupakan metode yang menelaah data di dalam Bahasa. Metode agih menggunakan teknik dasar BUL (Bagi Unsur Langsung), dilanjutkan dengan teknik lanjutan perluas dengan teknik dasar bagi unsur lansung, serta teknik lanjutan perluas. Dalam penjelasannya, metode agih digunakan untuk menganalisis bahasa atau tuturan direktif dalam cuitn@FiersaBesari yang berupa kta, frasa, serta kalimat. Lalu, teknik lanjutan menggunakan teknik perluas sebagai penjelas tuturan tersebut mengandung maksud yang seperti apa.

\section{HASIL DAN PEMBAHASAN}

Tindak tutur direktif merupakan suatu tuturan yang bersifat menyuruh mitra tutur atau followers dari @FiersaBesari agar melakukan sesuatu. Tindak tutur direktif merupakan jenis tuturan yang dimanfaatkan oleh penutur untuk menyuruh lawan atau mitra tutur agar melakukan sesuatu (Larassaty et al., 2016:432). Suruhan dalam tuturan direktif seperti, permohonan, perintah, serta pemberian saran.

Dalam cuitan@FiersaBesari dalam akun twitternya, ditemukan beberapa tuturan direktif. Berikut beragam cuitan yang mengandung tuturan direktif telah terkumpul dalam tabel berikut. 
Tabel 1 Tuturan Direktif Mengingatkan

\begin{tabular}{l} 
Tuturan \\
\hline Bersyukur bagus, mengeluh juga boleh. \\
Bersemangat bagus, malas-malasan juga \\
hak. Yang terpenting dijalani
\end{tabular}

Ada kalanya kita harus berhenti mengalah, ada kalanya juga kita harus berhenti dan mengalah

Udah, jangan dengki. Yang sendirian bukan berarti selalu kesepian. Yang berpasangan bukan berarti terus bahagia
"Kau tidak bisa memilih bagian mana dari masa lalumu yang ingin kau ubah dan bisa tahu bagaimana hasilnya". - The Orville

Hari ini, siap-siap dijatuhkan lagi. Habis itu, belajar bangkit lagi. Masalah makin berat, kita makin kuat
Maksud

Penutur bermaksud mengingatkan tentang selain bersyukur, menjadi manusia boleh mengeluh. Pun tidak perlu terus-terusan bersemangat, ingin bermalas-malasan juga boleh. Yang terpenting, tetap jalani hidup dengan baik.

Mengingatkan mengenai ada kalanya manusia melewati masa berhenti mengalah. Namun, ada juga masa di mana kita harus berhenti serta lebih baik mengalah.

Mengingatkan untuk tidak melulu memiliki rasa dengki kepada orang yang sudah memiliki pasangan. Pasalnya, orang yang masih sendirian, pun tidak selalu orang tersebut kesepian. Begitu sebaliknya, orang yang sudah berpasangan, tidak melulu terus bahagia Mengingatkan bahwa yang terjadi biarlah terjadi. Karena dasarnya kita tidak bisa memilih bagian-bagian di masa depan maupun masa lalu. Serta, kita tidak bisa mengatur apa yang sudah terjadi dan apa yang akan terjadi

Mengingatkan pada bahwa kita selalu siap untuk jatuh, kapanpun itu. Namun, kita juga harus siap bangkit saat itu juga. Meski masalah makin besar, itulah yang membuat kita jadi makin kuat.

Sesuai dengan pendapat dari (Larassaty et al., 2016) Tindak tutur direktif merupakan jenis tuturan yang dimanfaatkan oleh penutur untuk mitra tutur agar melakukan sesuatu. Jenis tuturan direktif mengingat mengajak mitra tutur untuk senantiasa ingat dan mengingatkan mengenai beragam hal. Seperti, bersyukur, mengalah, hingga selalu bangkit dan pantang menyerah.

Dari 35 data, sebanyak 15 data tuturan direktif menunjukkan pada jenis tuturan direktif mengingatkan. Tuturan direktif mengingatkan dalam penelitian ini merupakan 
tuturan terbanyak yang ditemukan. Terbukti dari 35 data terdapat 15 data atau tuturan yang mengandung tuturan direktif mengingatkan. Penggalan data tersaji dalam tabel di atas. Terdapat lima tuturan direktif jenis mengingatkan dalam tabel.

Wujud tindak tutur direktif mengingatkan masuk dalam jenis tindak tutur direktif memberi nasihat. (Saputri \& Rahmawati, 2020:250) menjelaskan bahwa tindak tutur direktif nasihat terdapat wujud meliputih menasehati, menyarankan, menyerukan, serta mengingatkan. Jelas bentuk mengingatkan dalam tuturan direktif yang ditemukan dalam penelitian ini termasuk dalam tindak tutur direktif nasihat dengan wujud mengingatkan.

Wujud tuturan direktif mengingatkan memiliki fungsi mengingatkan mitra tutur atau lawan bicara dari penutur. Fungsi mengingatkan di sini ditemukan dalam cuitan dari Fiersa kepada followers atau warganet.

Tabel 2 Tuturan Direktif Menasehati

\begin{tabular}{l|l}
\hline \multicolumn{1}{c|}{ Tuturan } & \multicolumn{1}{c}{ Maksud } \\
\hline $\begin{array}{l}\text { Jangan pesimis. Tapi tetap harus realistis. } \\
\text { berimbang }\end{array}$ & $\begin{array}{l}\text { Menasehati followers agar tetap } \\
\text { berpegang teguh pada kenyataan, } \\
\text { meskipun memiliki harapan. Agar, } \\
\text { menjalani kehidupan dengan optimis }\end{array}$ \\
\hline $\begin{array}{l}\text { Kalau dengan mengurangi kawan bisa } \\
\text { mengurangi drama, ya itu bagus-bagus } \\
\text { aja }\end{array}$ & $\begin{array}{l}\text { Menasehati followers bahwa meskipun } \\
\text { mengurangi teman, atau sama saja } \\
\text { dengan kehilangan teman itu tidak } \\
\text { mengapa. Selama tidak menambah drama } \\
\text { dalam sebuah pertemanan }\end{array}$ \\
\hline $\begin{array}{l}\text { Nasib baik dinikmati, nasib buruk } \\
\text { dijalani. Toh semua bakal berlalu }\end{array}$ & $\begin{array}{l}\text { Menasehati agar tetap menjalani hidup } \\
\text { dalam kondisi apapun. Entah sedang } \\
\text { bernasib baik maupun buruk. Semua akan } \\
\text { berlalu }\end{array}$ \\
\hline $\begin{array}{l}\text { Kamu bisa salah, orang lain bisa salah. } \\
\text { Tapi, merasa paling benar itu bukan } \\
\text { jawaban }\end{array}$ & $\begin{array}{l}\text { Menasehati agar tidak menjadi orang } \\
\text { yang merasa paling benar. Karena, } \\
\text { dasarnya manusia adalah tempatnya salah }\end{array}$ \\
\hline
\end{tabular}

Sebanyak 10 dari 35 data tuturan direktif, masuk pada jenis tuturan direktif menasehati. Empat data tersaji dalam tabel dari 10 data. Salah satu tuturan jenis menasehati yang meminta mitra tutur untuk menghadapi kenyataan, terus menjalani hidup apapun kondisinya, dan menasehati agar tidak menjadi orang yang paling benar. 
Sesuai dengan pendapat sebelumnya yakni dari (Larassaty et al., 2016) yang menyatakan bahwasannya tuturan direktif merupakan suatu usaha dari penutur yang meminta mitra tutur untuk melakukan sesuatu. Kali ini, melalui jenis tuturan direktif menasehati.

Tindak tutur menasehati merupakan bentuk atau wujud dari tindak tutur direktif memberi nasihat. (Umamy \& Irma, 2020:290) menjelaskan bahwa nasihat merupakan sesuatu hal yang berhubungan dengan hal baik. Sehingga, simpulannya, dalam wujud tuturan direkif menasihati, penutur atau Fiersa memberikan sebuah ajaran atau nasihat kepada lawan bicara atau mitra tutur Fiersa yakni followersnya.

Tuturan nasihat oleh Fiersa menunjukkan hal-hal baik yang dapat didengar dan dilakukan oleh mitra tutur atau warganet. (Sumarsih et al., 2018:57) menyatakan bahwa tuturan menasehati memiliki fungsi agar mitra tutur melakukan hal yang terdapat dalam tuturan Fiersa.

Tabel 3 Tuturan Direktif Mengajak

\begin{tabular}{l|l}
\hline \multicolumn{1}{c|}{ Tuturan } & \multicolumn{1}{c}{ Maksud } \\
\hline Ditahan dulu nyinyirnya coba & $\begin{array}{l}\text { Mengajak agar menahan untuk tidak } \\
\text { seenaknya dalam berkomentar khususnya } \\
\text { di media sosial }\end{array}$ \\
\hline $\begin{array}{l}\text { Dulu saya bodoh. Sekarang belum pintar. } \\
\text { Tapi, setiap harinya belajar }\end{array}$ & $\begin{array}{l}\text { Mengajak agar terus belajar, supaya yang } \\
\text { awalnya bodoh atau kurang wawasan } \\
\text { menjadi tahu, meskipun begitu jangan } \\
\text { berpuas diri, yang penting terus belajar }\end{array}$ \\
\hline $\begin{array}{l}\text { Orang berpendapat bukan berarti pengin } \\
\text { pansos. Orang tidak tahu bukan berarti } \\
\text { mainnya kurang jauh. Orang tidak } \\
\text { sependapat bukan berarti harus di-bully }\end{array}$ & $\begin{array}{l}\text { Mengajak untuk menghargai satu sama } \\
\text { lain. Entah itu menghargai orang yang } \\
\text { sedang berpendapat, orang tidak tahu, } \\
\text { bahkan orang yang tidak sependapatpun, } \\
\text { tetap harus dihargai. Jangan merasa } \\
\text { menjadi orang superior. }\end{array}$ \\
\hline
\end{tabular}

Jenis tuturan direktif selanjutnya yakni, mengajak. Jenis ini mengajak mitra tutur untuk senantiasa terus belajar, menghargai satu sama lain, serta agar tidak seenaknya melontarkan komentar tidak masuk akal dalam menggunakan media sosial. Jenis mengajak ini ditemukan jenis 6 dari ke 35 data tuturan direktif. Ketiga data yang tersaji dalam tabel, sebagian dari keseluruhan data jenis mengajak.

Pada dasarnya, wujud tuturan mengajak merupakan suatu tuturan direktif yang tujuannya mengajak mitra tutur untuk melakukan sesuatu. Fungsi tindak tutur direktif 
mengajak yakni untuk mengajak mitra tutur atau lawan bicara penutur untuk melakukan hal yang dituturan oleh penutur (Sumarsih et al., 2018:56). Dalam penelitian ini maksudnya, Fiersa mengajak warganet ataupun pengikutnya dalam twitter untuk melakukan yang ia tuturkan.

(Ramadhani \& Santoso, 2019:48) menjelaskan mengenai fungsi tindak tutur mengajak bahwa tuturan direktif mengajak memiliki fungsi mengajak yang digunakan penutur untuk mengajak mitra tutur. Seperti data dalam table yang pertama, Fiersa mengajak mitra tutur untuk tidak nyinyir. Atau, untuk tidak melontarkan komentar tak sedap kepada orang lain.

Tabel 4 Tuturan Direktif Menegur

\begin{tabular}{l|l}
\hline \multicolumn{1}{c|}{ Tuturan } & \multicolumn{1}{c}{ Maksud } \\
\hline $\begin{array}{l}\text { Kenapa harus muter-muter kalau bisa } \\
\text { dipermudah? Karena gengsi tentu saja }\end{array}$ & $\begin{array}{l}\text { Menegur untuk tidak selalu gengsi, } \\
\text { tujuannya agar segalanya jadi lebih } \\
\text { mudah, sehingga, tidak melulu } \\
\text { mengedepankan ego serta gengsi }\end{array}$ \\
\hline $\begin{array}{l}\text { Dunia lagi banyak huru-hara. Kurang etis } \\
\text { kalau hura-hura. }\end{array}$ & $\begin{array}{l}\text { Menegur untuk menghargai keadaan yang } \\
\text { sedang menimpa sesama. Akan lebih baik } \\
\text { bila kita memperhatikan situasi dan } \\
\text { kondisi untuk bersenang-senang. }\end{array}$ \\
\hline
\end{tabular}

Jenis tuturan direktif terakhir yakni menegur. Tuturan ini paling sedikit diantara ketiga jenis yang lain. Dalam tabel disajikan dua jenis tuturan menegur dari empat data yang ditemukan.

Wujud tuturan direktif menegur terletak dalam tindak tutur direktif kritikan. Hal tersebut dijelaskan (Saputri \& Rahmawati, 2020:251) bahwa wujud tindak tutur direktif kritikan meliputi, menyindirm menegur, mengumpat, serta marah. Fungsinya penutur di sini yakni Fiersa ingin memberikan sebuah kritikan dengan cara menegur kepada warganet. Seperti salah satu bentuk tuturan yakni "Dunia lagi banyak huru-hara. Kurang etis kalau hura-hura,". Tuturan tersebut memiliki maksud bahwa penutur atau Fiersa ingin warganet menghargai situasi dan kondisi saat pandemi. Sedikit kurang etis bila bersenang-senang ketika keadaan sedang dilanda pandemi. 
Apabila disajikan dalam bentuk presentasi jumlah data yang ditemukan, dapat disimpulkan sebagai berikut. Dimulai dari tuturan mengingatkan sebanyak $43 \%$. Selanjutnya, tuturan menasehati sebanyak 29\%. Tuturan mengajak sebanyak $17 \%$. Terakhir tuturan yang paling sedikit yakni menegur sebanyak $11 \%$.

\section{E. KESIMPULAN}

Berdasarkan hasil pembahasan, dapat disimpulkan bahwa tuturan direktif yang paling mendominasi dalam akun twitter @ FiersaBesari adalah jenis tuturan direktif mengingatkan, lalu di susul menasehati, mengajak, dan menegur. Serta, sesuai dengan tujuan tuturan direktif yakni, (Islamiati, Rita Arianti, 2020) yang menyatakan bahwa tindak tutur direktif merupakan suatu tuturan yang dapat memberikan efek berupa tindakan yang diinginkan oleh penutur. Kelebihan dari penelitian ini, menganalisis tuturan direktif hanya pada satu akun, sehingga memiliki pandangan sudut pandang pertama dalam penelitian. Kekurangannya, karena hanya satu akun, menjadikan penelitian ini hanya berfokus pada sudut pandang orang pertama saja. Tidak menganalisis pada mitra tutur sebagai sudut pandang kedua.

\section{F. SARAN}

Saran untuk penelitian selanjutnya, manfaatkan media sosial sebagai media atau sumber data penelitian. Selain mudah, efektif, serta efisien, dapat menemukan keberagaman bentuk tuturan oleh warganet. Selain itu, kaji lebih dalam lagi menggunakan jenis tindak tutur yang lain seperti, tindak tutur ekspresif, komisif, dan lainlain. Selain itu, tidak hanya tindak tutur, dapat menggunakan kajian pragmatik yang lain.

\section{DAFTAR PUSTAKA}

Achsani, F. (2019). TINDAK TUTUR DIREKTIF DAN IMPLIKATUR KONVENSIONAL DALAM WACANA MEME DILAN. Jurnal IMAJERI, 01(2), $1-10$.

Fitri, A., Budiono, \& Shalima, I. (2019). Tindak Tutur Direktif dalam Kumpulan Cerpen Lukisan Kaligrafi Karya A . Mustofa Bisri serta Implementasi Pembelajaran Teks 
Anekdot di SMA. Repetisi: Riset Pendidikan Bahasa Dan Sastra Indonesia, 2(1), $36-52$.

Ilmiah, N., \& Affandy, A. N. (2017). Tindak Tutur Direktif Kampanye Calon Gubernur DKI Jakarta 2016. Stilistika, 10(2), 101-115.

Islamiati, Rita Arianti, G. (2020). Tindak Tutur Direktif dalam Film Keluarga Cemara Sutradara Yandy Laurens dan Implikasi Terhadap Pendidikan. Jurnal Pendidikan Rokania, 5(2), 258-270.

Larassaty, S., R, S., \& Ganti, E. (2016). REPRESENTASI TINDAK TUTUR DIREKTIF BAHASA INDONESIA SISWA KELAS XI SMA NEGERI 15 PADANG. Jurnal Pendidikan Bahasa Dan Sastra Indonesia, 5(2), 431-437.

Nurkamto, J., Baidan, N., \& Sumarlan. (2016). Pragmatic Study of Directive Speech Acts in Stories in Alquran. Advances in Language and Literary Studies, 7(5), 79-84. https://doi.org/10.7575/aiac.alls.v.7n.5p.78

Qomariyah, L. (2017). TINDAK TUTUR DIREKTIF (TTD) GURU DALAM PEMBELAJARAN BAHASA ARAB. Arabi: Journal of Arabic Studies, 2(1), 118.

Ramadhani, A. D., \& Santoso, J. (2019). ANALISIS TINDAK TUTUR DIREKTIF DALAM MEDIA SOSIAL TWITTER @ SBYUDHOYONO. E-Journal Student: Sastra Indonesia, 8(4), 44-50.

Saputri, K. E., Bagiya, \& Purwanto, J. (2018). ANALISIS TINDAK TUTUR DIREKTIF DALAM NOVEL MISTERI PATUNG GARAM KARYA RUWI MEITA DAN PEMBELAJARANNYA DI SMA. Surya Bahtera Volume, 6(50), 31-40.

Saputri, U. I., \& Rahmawati, L. E. (2020). Analisis Bentuk Tindak Tutur Direktif Dalam Dialog Film "Rembulan Tenggelam Di Wajahmu” Karya Tere Liye. Jurnal KIBASP (Kajian Bahasa, Sastra Dan Pengajaran), 3(2), 249-260.

Sudarto. (2018). TINDAK TUTUR DIREKTIF DALAM SURAT DINAS IMPLEMENTASINYA SEBAGAI BAHAN AJAR BAHASA INDONESIA. Stilistika, 4(2), 83-92.

Sudaryanto. (2015). Metode dan Aneka Teknik Analisis Bahasa (1st ed.). Sanata Dharma University Press.

Sumarsih, N., Bahasa, B., \& Istimewa, D. (2018). STRATEGI DAN FUNGSI TINDAK 
TUTUR DIREKTIF DALAM POSTER PENDIDIKAN.

Umamy, F., \& Irma, C. N. (2020). ANALISIS TINDAK TUTUR DIREKTIF DALAM NOVEL ORANG- ORANG BIASA KARYA ANDREA HIRATA. Jurnal Pendidikan, Bahasa, Sastra, Dan Budaya, 1, 782-791.

Waljinah, S., Prayitno, H. J., Purnomo, E., Rufiah, A., \& Kustanti, E. W. (2019). TINDAK TUTUR DIREKTIF WACANA BERITA ONLINE: KAJIAN MEDIA PEMBELAJARAN BERBASIS TEKNOLOGI DIGITAL. Jurnal Pendidikan Bahasa Dan Sastra Indonesia, 2(2), 118-129.

Wulansari, Y., \& Suhartini, C. (2015). DIRECTIVE SPEECH ACTS REALIZATION OF. ENGLISH REVIEW: Journal of English Education, 3(2), 223-229. 